\title{
ANÁLISE CONTRASTIVA DE TEXTOS EM SALA DE AULA
}

\author{
Susanah Yoshimi Watanabe Romero' \\ Mariana Spagnolo Martins ${ }^{2}$
}

Resumo: Nosso objetivo neste artigo é analisar fenômenos encontrados em textos dos gêneros poema e música, que retratam a linguagem popular, os quais se aproximam da fala dos alunos e, a partir desses dados, identificar o que, segundo a norma-padrão, apresentaria desvios gramaticais. A partir das observações dos textos, buscamos identificar como o ensino de português na escola deve abranger as diferentes possibilidades de uso da língua, que contemplam a modalidade culta, a norma-padrão e a variação linguística. Para isso, utilizamos os estudos de Carlos Alberto Faraco (2002; 2008) e Stella Maris Bortoni-Ricardo (2004) como fundamentação do conceito de norma e da metodologia dos Contínuos de Letramento, Monitoração e Estilística. Para contrapor as teorias da Pedagogia da Variação (FARACO, 2008; BORTONI-RICARDO, 2004), apresentamos os conceitos gramaticais dos fenômenos analisados, com base nas gramáticas de Mauro Ferreira (2007) e Evanildo Bechara (2015). Respaldados nas teorias, partimos para a análise dos materiais, que consistem em duas músicas populares e quatro poemas modernistas brasileiros. Nesse contexto, observamos como os autores empregam as colocações pronominais, a seleção lexical e as pessoas do discurso, a princípio fora da norma-padrão, mas coerente para os alunos. Dessa forma, criamos o contraste entre norma-padrão e norma culta, apresentando para os estudantes as várias formas de adequação.

Palavras-chave: Poema e música; Pedagogia da Variação; Sociolinguística; Normas.

\section{Introdução}

A preocupação de professores e pesquisadores da área de Ensino e de Variação Linguística geralmente consiste em como ensinar ou inserir o ensino das variedades da língua em sala de aula. Ainda há certo preconceito em valorizar as variedades estigmatizadas que a maioria dos alunos, normalmente de classes média ou baixa, apresenta no dia a dia. O conceito de ensino da língua portuguesa ainda é sobre o que é certo ou errado na fala e na escrita dos alunos. Por outro lado, vários desvios

\footnotetext{
${ }^{1}$ Graduada em Letras Português, Mestra e Doutoranda em Estudos da Linguagem (Universidade Estadual de Londrina).E-mail: susanah.yoshimi@hotmail.com

${ }^{2}$ Graduada em Letras Português, Especialista em Língua Portuguesa, Mestra e Doutoranda em Estudos da Linguagem (Universidade Estadual de Londrina).E-mail: mariana.spagnolo@hotmail.com
} 
da norma-padrão não são tão perceptíveis para a maioria dos estudantes que não tem acesso direto a essas variedades.

A teoria de certo e de errado é direcionada à norma-padrão, variante de prestígio da sociedade brasileira, mas que foge à realidade utilizada pelos falantes de português, gerando o famoso tabu de que "o brasileiro não sabe falar português". Uma ideia um tanto tendenciosa e infeliz, pois nesta concepção defende-se o uso utópico de uma língua homogênea, padrão e inflexível, o que caracteriza a infelicidade do tabu. No entanto, concordamos com a ideologia escondida nessa concepção, o fato de não se falar um português, podemos adequar a crença para a nossa realidade, talvez afirmar que: "nós brasileiros não falamos apenas um português, mas vários”.

O substantivo "português” não designa um objeto homogêneo que seja definido apenas por critérios linguísticos, uma língua não se conceitua linguisticamente, o nome singular português não retrata algo único, mas uma realidade plural, isto é, o português são vários, pois a língua portuguesa é a união de variedades linguísticas. As multifaces da língua compõem diferentes cenários linguísticos, apresentando construções mais monitoradas e outras vezes menos, considerando o contexto de uso. A comprovação desta teoria é o fato de falantes de diferentes comunidades linguísticas se reconhecerem como falantes de uma mesma língua, mesmo quando não há entre eles inteligibilidade mútua, ou seja, cada variedade constitui uma norma linguística.

Sobre o assunto, trazemos as teorias e reflexões do linguista Carlos Alberto Faraco $(2002 ; 2008)$, que apresenta as definições e distinções de normas. Na sequência, como teoria complementar e pragmática das reflexões de Faraco, temos os Contínuos de Letramento, Monitoração e Estilística da autora Bortoni-Ricardo (2004), o que caracteriza como uma forma de integrar a Pedagogia da Variação nas escolas brasileiras. Ademais, adentramos na análise dos textos: "Balada do amor através das idades", de Carlos Drummond de Andrade (1930); "Samba da volta” (1974) e "Poema enjoadinho" (1954), de Vinícius de Moraes; “O menino que carregava água na peneira”, de Manoel de Barros (1999); “A educação pela pedra”, de João Cabral de Melo Neto (1997); e a música “Trevo”, de Anavitória (2016). A partir desses materiais, levantamos os fenômenos linguísticos que correspondem à linguagem popular e fogem do padrão normativo ensinado nas escolas.

\section{Conceitos de Normas Culta e Padrão}

Antes de diferenciar norma culta de norma-padrão, é necessário conhecer o que é norma: tudo aquilo considerado como lei, regra ou como elementos próprios do uso natural (FARACO, 2008). Assim, em relação à Linguística, norma é um conjunto de regras que determinam o uso da língua: existem a padrão, a não padrão e a culta, que faz parte nas normas normais e que é resultado da prática da língua em meios sociais considerados cultos. Já a norma-padrão é o modelo convencional estipulado 
por gramáticos, a qual segue os preceitos da transformação da língua por meio de seus falantes e por isso é sempre atualizada, de acordo com o que os gramáticos julgam como adequado. Por sua vez, a norma não padrão é a que destoa das regras convencionais estipuladas por um grupo de prestígio de falantes do português.

Segundo Faraco (2008), a norma culta diz respeito à variedade utilizada pelas pessoas mais próximas da modalidade escrita e, portanto, possuem uma fala correspondente dessas práticas. Faraco esclarece que o termo "norma culta", como foi dito, designa a variedade utilizada pelas pessoas que possuem mais contato com a "cultura escrita”, fato que origina essa denominação. No que tange à norma-padrão, o linguista define como aquela carregada de preconceitos em relação às demais variedades e com o objetivo - como o próprio nome diz - da padronização da língua, considerando tudo o que é diferente como erro.

O assunto de norma-padrão estabelece o conceito de certo e errado, esses conceitos rígidos não fazem sentido para parte dos falantes, de acordo com Faraco, os preceitos normativos estão muito distantes do senso linguístico popular e, por isso, a dificuldade de serem incorporados. Assim, a distinção entre norma culta e norma-padrão pode ser resumida em dois pontos de vista distintos: uma realidade heterogênea da língua, a norma culta; e a crença na homogeneização da língua, ou seja, a norma-padrão.

De acordo com Faraco (2008), as normas são variedades da língua portuguesa e não existe uma melhor que a outra, mas situações em que o uso de uma variedade se torna adequado ou não. A fala é a caracterização do homem, em contextos sociais, históricos, psicológicos, pessoais, profissionais, entre diversas outras situações corriqueiras que todo falante de qualquer língua está disposto a passar. A fala pode ser empregada utilizando-se diferentes variedades linguísticas de acordo com a situação em que o falante se encontra, seria incoerente existir apenas um estilo correto de fala, já que todas as outras formas de dizeres também são compreensíveis e, por vezes, mais bem aceitas do que a modalidade padrão da língua. O normal é utilizar variedades da língua de acordo com cada situação, ou contínuos, o que veremos a seguir.

De acordo com Faraco (2008), o conceito de norma normal pode ser considerado o conjunto de fenômenos linguísticos (fonológicos, morfológicos, sintáticos e lexicais) comuns entre os falantes de uma determinada comunidade de fala. $\mathrm{Ou}$ seja, a norma corresponde àquilo que é normal, sabe-se que a língua é heterogênea, portanto, há inúmeras normas normais que formam a língua portuguesa.

A diversidade linguística pode ser explicada por meio das redes de relações sociais que estabelecem o interior de cada comunidade de fala, as chamadas comunidades de práticas. Faraco (2008) define o termo como um agregado de pessoas que partilham experiências coletivas em diferentes práticas, como no contexto de trabalho, escolas, igrejas, cotidiano da rua, família etc. Em cada uma dessas comunidades, costuma haver modos particulares de fala, os falantes se adequam aos contextos sociais, ou seja, variam de acordo com a situação em que 
se encontram, fato que justifica o apelido que Faraco designou aos falantes de uma língua: somos todos camaleões linguísticos. O conceito de norma normal, de acordo com o linguista, sinaliza que, mesmo havendo variação, cabe ao falante se adaptar às normas daquela comunidade de prática.

Para Faraco (2002), a questão da chamada "norma-padrão" reitera que a língua portuguesa vai muito mal no Brasil, retornando certos discursos sociais e o senso comum sobre a língua. Logo, é necessário desenvolver um projeto de reconstrução das referências padronizadas, além da artificialidade e da rigidez, o que traria consequências positivas que poderiam "desembaraçar os nós" que afetam o ensino e o uso do padrão no Brasil. Assim, Faraco defende que a nossa sociedade é diversificada e estratificada, existindo inúmeras normas linguísticas, que servem como fator de identificação ao grupo, gerando um senso de pertencimento graças à forma de falar característica, ou seja, as formas linguísticas estão agregadas a valores socioculturais. Além disso, é inevitável o contato entre essas interinfluências diversas, o que gera as normas hibridizadas.

Segundo Faraco, a norma culta são os fatos linguísticos do grupo social mais diretamente ligada à cultura, ou seja, às atividades de escrita, que controlam o poder social e as situações formais de fala e escrita, demonstrando um posicionamento privilegiado. Por outro lado, o autor afirma que não existe grupo humano sem cultura, sendo necessário considerá-la em seu sentido amplo, que mobiliza uma vasta gama de modos de ser, agir, pensar e dizer.

Por sua vez, a norma-padrão aparece como um processo fortemente unificador, que visa uma relativa estabilização linguística, a fim de neutralizar a variação e controlar a mudança. Porém, é um fenômeno relativamente artificial e abstrato, pois há, em sua codificação, um processo de relativo apagamento de marcas dialetais. Assim, o padrão nunca conseguirá suplantar a diversidade, pois é impossível homogeneizar a cultura e a sociedade e estancar o movimento e a história. Por outro lado, o padrão continua tendo, por coação social, um efeito unificador sobre as demais normas, não estando isento de receber influência.

Dessa maneira, Faraco demonstra que se enraizou na nossa cultura uma atitude purista e normativista que procura por erros, mesmo em textos correntes na norma culta e em importantes autores, pois qualquer fenômeno pode fugir do estipulado pelos compêndios gramaticais conservadores. Isso tem causado diversos males, tanto no ensino quanto no uso de um padrão desejável, pois o que deveria ser um elemento sociocultural positivo se tornou um pesado fator de discriminação e exclusão sociocultural.

Assim, a língua é vista com um caráter homogêneo, tratando a variação e a mudança como desvios, erros e "não-língua", o que os linguistas têm combatido. O caráter excessivamente artificial do padrão brasileiro gera os preconceitos, discussão do tópico da teoria dos contínuos, de Bortoni-Ricardo (2004), na qual considera o conceito de erro, fato que possibilita traçar o perfil sociolinguístico dos alunos. 


\section{A teoria dos contínuos}

A proposta de Bortoni-Ricardo (2004) busca distribuir as variedades em três modelos que se entrecruzam: o contínuo rural-urbano, o contínuo de oralidade e letramento e o contínuo da monitoração estilística. Dessa maneira, a autora questiona o que a sociedade tacha como erro na fala das pessoas, entretanto, a teoria da Sociolinguística considera o erro como uma questão de inadequação que decorre das imagens que os interlocutores fazem uns dos outros, dos papéis sociais que estejam desempenhando e das normas e crenças vigentes. A tarefa do professor deveria ser avaliar o prestígio e mostrar as circunstâncias em que a variante é adequada, para combater o estigma associado às formas linguísticas de pouco prestígio social.

O contínuo de urbanização, o qual a autora classifica em variedades rurais isoladas, são aquelas em que há o predomínio de traços descontínuos, essas áreas são definidas por uma geografia isolada, excluídas por rios e montanhas e de difícil acesso aos meios de comunicação. Em contrapartida, há as áreas rurbanas ${ }^{3}$, definidas pela autora como polos intermediários entre os falares rurais e os urbanos. Por falares urbanos, a autora considera aqueles que sofreram fortes influências da padronização da língua, com acesso constante aos meios de comunicação (livros, revistas, jornais, gramáticas, entre outras formas de letramento). Assim, a outra ponta do contínuo, a qual se divide em variedades rurais > área rurbana > variedades urbanas padronizadas. Neste contínuo, a autora secciona os traços graduais e descontínuos, de acordo com a representação do contínuo de urbanização, já que as regras fonológicas caracterizam o português e podem ser classificadas como graduais e descontínuas, inserindo, pois, qualquer falante do português brasileiro no contínuo de urbanização.

Os traços descontínuos são aqueles itens linguísticos (fonéticos, lexicais, morfossintáticos) típicos dos falares rurais, como, por exemplo: inté (até), prantei (plantei), artura (altura), sor (sol), entre outros. Essas construções, como podem ser observadas, fogem ao padrão culto da língua e são mais comuns em comunidades rurais. No entanto, não podem ser consideradas erradas, já que cada forma apresenta uma explicação de acordo com as mudanças e variações linguísticas, como no caso do inté, que é um arcaísmo preservado em falares rurais, já que há registros desse item lexical em textos de Camões, datado de 1572. A expressão é considerada descontínua, porque o seu registro é comum em falares rurais e, quando se aproxima de centros urbanos, é desprestigiada ou mesmo inexistente.

O contínuo de oralidade-letramento obedece ao mesmo raciocínio do anterior, com dois extremos: a ponta da oralidade e a de letramento. Os eventos de oralidade estão relacionados à fala espontânea, natural, sem uma preparação, o que a diferencia de um evento de letramento. Neste caso, o falante está apoiado a um texto escrito, tendo como base um estudo ou uma preparação feita previamente.

${ }^{3}$ Segundo a teoria de Bortoni-Ricardo (2004), as áreas "rurbanas" correspondem a linguagem intermediária da zona rural e urbana, por isso a construção da nomenclatura. 
Já eventos de oralidade são conversas em famílias, bares, festas, logo, a situação informal do discurso. Assim como no contínuo de urbanização, no de oralidade-letramento não existem fronteiras bem marcantes, de acordo com Bortoni-Ricado (2004, p. 62) "as fronteiras são fluídas e há muitas sobreposições”.

Como proposta de facilitar a análise do português, a autora cria o terceiro contínuo, nomeado como contínuo de monitoração estilística, em que há dois extremos, o primeiro é a fala menos monitorada, como nos eventos de oralidade, e o segundo a mais monitorada, como os eventos de letramento. Os contínuos de Bortoni-Ricardo obedecem aos estilos de monitoramento da fala, ou seja, situações que exigem do falante uma linguagem mais padronizada e situações que expressam um falar menos monitorado, visto que o ambiente, o interlocutor e o tópico da conversa influenciam na monitoração.

Em paralelo com os contínuos de Bortoni-Ricardo (2004), também é necessário discorrer a respeito dos traços descontínuos e graduais, muito presentes na modalidade oral, mas também transpostos para a modalidade escrita e, portanto, devem ser trabalhados pela escola.

Nas palavras da autora,

\begin{abstract}
Alguns itens são típicos dos falares situados no polo rural e que vão desaparecendo à medida que nos aproximamos do polo urbano. Dizemos, então, que esses traços têm uma distribuição descontínua porque seu uso é “descontinuado" nas áreas urbanas. Há outros traços [...] que estão presentes na fala de todos os brasileiros e, portanto, se distribuem ao longo de todo o contínuo. Esses traços, ao contrário dos outros, têm uma distribuição gradual. Vamos chamá-los de traços graduais. Observe que os traços descontínuos são os que recebem a maior carga de avaliação negativa nas comunidades urbanas (BORTONI-RICARDO, 2004, p. 53).
\end{abstract}

Portanto, dentro dos contínuos de urbanização, de oralidade-letramento e de monitoração estilística, percebemos tanto os traços descontínuos quanto os graduais, que mostram o nível de estigma das variantes utilizadas pelos falantes. Além disso, podem aparecer transpostas para a modalidade escrita.

\title{
4 Pedagogia da Variação
}

O ensino de português sempre teve a gramática como elemento central da tradição escolar brasileira. A vassalagem ao modelo de língua lusitana, característica dos séculos passados, ainda está em vigor nas escolas brasileiras. A cultura do erro, a crença em uma língua homogênea e a desvalorização de normas normais por muitos professores que prejudicam os alunos ao ensiná-los que não dominam sua língua materna.

A Pedagogia da Variação (BORTONI-RICARDO, 2004; FARACO, 2008) ainda está em processo de discussão e aperfeiçoamento, não por não ter uma metodologia 
aplicável ou teorias concretas, mas devido ao ensino de português ainda estar pautado na crença tradicional de língua, que defende a norma-padrão como a única forma correta de falar e refletir sobre o português.

Nas palavras de Faraco (2008, p. 128): “até hoje continuamos a aceitar que pretensas autoridades gramaticais, fundadas no puro arbítrio, digam a nós, brasileiros, como devemos falar e escrever a língua que nos pertence”. Desta forma, instaura-se um desafio aos sociolinguistas e pesquisadores: dissipar a cultura do erro e a ideologia do gramatiquês, assumindo, assim, a propriedade que nos pertence - a língua brasileira.

Vale lembrar que a Sociolinguística e a Pedagogia da Variação não são contra o ensino da gramática normativa, apenas querem colocá-la em seu devido lugar, como mais uma variedade da língua com importância nas modalidades escritas e falada as quais exigem uma padronização do discurso, assim como as demais variedades linguísticas, ou seja, o ensino de gramática não deve ser superior ao ensino de português.

O desejo dos pesquisadores é demonstrar que as formas de comunicações verbais e não verbais são diversas e podem ser trabalhadas em gêneros textuais e orais que são pertinentes à realidade dos alunos. A escola deveria preparar os estudantes para situações em que realmente farão uso dos conhecimentos linguísticos trabalhados nas aulas de português, neste sentido, aplica-se a importância de estudar uma gramática contextualizada nos diversos gêneros textuais que circulam no dia a dia. Diferente do modelo tradicional que, além de distanciar os alunos da língua portuguesa, apresentando-a de maneira abstrata e de difícil compreensão, ainda provoca nos estudantes o preconceito linguístico, pois desmerece variedades ditas incultas e engrandece uma variedade dita padrão.

Novamente, Faraco (2008) nos esclarece que

\begin{abstract}
Se queremos bem ensinar a língua, temos de ter bastante clareza sobre isso, não misturando o nível estrutural e os valores sociais, entendendo que aqueles que falam variedades desvalorizadas socialmente não são, por isso, linguisticamente inferiores. E, ao mesmo tempo, precisamos ter um olhar crítico sobre os índices sociais de valor (positivos ou negativos) que recobrem as variedades linguísticas, para que a norma culta/comum/ standard fique adequadamente situada em meio às demais variedades $\mathrm{e}$ não se torne nem uma camisa de força, nem um fator de discriminação (FARACO, 2008, p. 136).
\end{abstract}

A essência de uma pedagogia da Variação está pautada nos valores ditados acima, os quais podem ser resumidos em: respeitar e compreender as funções da língua em cada contexto de uso. Quando é discutida a proposta de adequação no ensino de português, não significa "aceitar tudo", mas respeitar todas as variedades de língua e evitar o preconceito linguístico. O real fator a ser combatido é o paradigma de unificação da língua, propondo a substituição da ideologia anacrônica 
de normatização pelo respeito consciente da diversidade linguística, tarefa difícil, mas coerente, logo aplicável.

\section{Colocação pronominal em algumas gramáticas}

Um exemplo de como a norma-padrão é ensinada pela escola é a colocação pronominal. Para observarmos melhor esse fenômeno, trazemos a conceituação de duas gramáticas, a fim de compará-las e utilizá-las posteriormente na análise. A gramática de Mauro Ferreira (2007), intitulada Aprender e praticar gramática, a qual dedica quinze páginas ao conteúdo de colocação pronominal, entre sete de teoria e oito de exercícios. $\mathrm{O}$ autor inicia com a retomada de pronomes oblíquos átonos, pontuando a importância de se conhecer:

A colocação dos pronomes oblíquos átonos é um aspecto gramatical
relacionado à adequação da frase ao padrão formal - e tradicional - da
língua. Convém, portanto, conhecer as orientações básicas relativas ao
assunto (FERREIRA, 2007, p. 603).

Isso demonstra a preocupação do autor com o aspecto da adequação linguística a ser desenvolvida pelo aluno. A seguir, Ferreira (2007) aborda a próclise obrigatória, os fatores de próclise que exercem influência sobre os pronomes oblíquos, fazendo com que se posicionem antes do verbo, quais sejam: palavras negativas (não, nunca, nada etc.), advérbios (hoje, agora, lá, talvez, rapidamente etc.), pronomes relativos (que, quem, qual, onde etc.), pronomes indefinidos (tudo, alguém, outros etc.) e as conjunções subordinativas (que, embora, como etc.).

Além disso, o gramático afirma que "a próclise também é obrigatória em orações iniciadas por palavras interrogativas ou exclamativas e em orações com preposição em + gerúndio" (FERREIRA, 2007, p. 605). Sobre a próclise opcional, o autor ensina que se pode optar em relação à ênclise nos casos em que o verbo não inicia a oração ou com o verbo no infinitivo não-flexionado precedido de palavra negativa ou preposição.

Quanto à mesóclise, Ferreira (2007) também se preocupa com a adequação, afirmando que "só é obrigatória quando se combinam dois fatores: verbo no futuro (do presente ou do pretérito iniciando a oração) e ausência de palavra atrativa exigindo próclise" (FERREIRA, 2007, p. 606). Sobre a ênclise, o autor explica que só é obrigatória quando o verbo inicia a oração e, no interior da oração, é precedido de pausa (silêncio na fala, sinal de pontuação na escrita), especificamente sobre os pronomes o, a, os, as, Ferreira demonstra que podem sofrer alterações de forma, dependendo da terminação do verbo. Se terminada em vogal, os pronomes não se modificam, porém se em -r, -s ou -z, perde a terminação e assume a forma lo(s) e la(s); por sua vez, quando terminada em som nasal, assume a forma no(s) e na(s).

Por fim, Ferreira discorre a respeito da colocação pronominal nas locuções verbais, em que a estrutura é verbo auxiliar + verbo principal infinitivo/gerúndio/ 
particípio, em que a norma admite três possibilidades: antes da locução verbal (desde que não inicie a oração); entre os dois verbos da locução; e depois do verbo principal (desde que não seja um particípio).

Passando para a gramática de Evanildo Bechara (2015), que dedica cinco páginas ao conteúdo de colocação pronominal, defendendo, inclusive, que foi criada

a falsa teoria da 'atração' vocabular do não, do quê, de certas conjunções e tantos outros vocábulos. [...] chegou-se à conclusão de que muitas das regras estabelecidas pelos puristas ou estavam erradas, ou se aplicavam em especial atenção ao falar lusitano [...] A Gramática, alicerçada na tradição literária, ainda não se dispôs a fazer concessões a algumas tendências do falar de brasileiros cultos, e não leva em conta as possibilidades estilísticas que os escritores conseguem extrair da colocação de pronomes átonos. Daremos aqui apenas aquelas normas que, sem exagero, são observadas na linguagem escrita e falada das pessoas cultas. Não se infringindo os critérios expostos, o problema é a questão pessoal de escolha, atendendo-se às exigências da eufonia e do ritmo frasal (BECHARA, 2015, p. 605).

Portanto, mesmo com um terço da quantidade de páginas dedicadas ao assunto por Ferreira, Bechara (2015) demonstra a preocupação em falar a respeito das falsas teorias criadas pelos puristas, com base na tradição literária, especialmente lusitana. Logo, podemos pensar não só em adequação, mas também em escolhas pessoais, assim como na situação do vernáculo, com suas variantes. Além disso, Bechara mostra como seu uso não é vitorioso na língua exemplar e mormente na modalidade escrita, sendo desrespeitado também no nosso falar espontâneo, de modo que a próclise, por exemplo, nos textos literários, aparece quando não se quer quebrar a corrente contínua do pensamento.

Assim, Bechara passa a discorrer sobre os critérios para a colocação dos pronomes. Primeiramente em relação a um só verbo, mostra que não se inicia o período por pronome átono. A seguir, ensina que não se pospõe, em geral, pronome átono a verbo flexionado em oração subordinada. Porém, quando se trata de orações coordenadas, mostra que às vezes ocorre a ênclise do pronome átono na segunda oração e também quando na subordinada se intercalam palavras ou oração, exigindo uma pausa antes do verbo. Bechara ainda pondera que não se pospõe pronome átono a verbo modificado diretamente por advérbio (sem pausa entre os dois, com ou sem vírgula), ou precedido de palavra de sentido negativo, bem como de pronome ou quantitativo indefinidos, enunciados sem pausa.

Além disso, o autor assevera que não se pospõe pronome átono a verbo no futuro do presente e futuro do pretérito (condicional), bem como não se pospõe ou intercala pronome átono a verbo flexionado em oração iniciada por palavra interrogativa ou exclamativa, ou não se antepõe pronome átono a verbo no gerúndio inicial de oração reduzida. Porém o autor lembra que pode ocorrer a próclise se o verbo estiver precedido da preposição em ou no infinitivo preposicionado. 
Quanto à colocação em relação a uma locução verbal, Bechara ensina que, se os princípios já expostos não forem contrariados, o pronome átono pode aparecer proclítico ou enclítico ao verbo auxiliar ou enclítico ao verbo principal. Porém, é necessário saber que não se usa a ênclise ao auxiliar haver de + infinitivo, além de que, entre os brasileiros, tanto na fala quanto na escrita, ocorre com mais frequência o pronome átono proclítico ao verbo principal, sem hífen. Sobre a posição fixa da próclise, Bechara afirma que a tradição fixou nos casos com o gerúndio precedido da preposição em e nas orações exclamativas e optativas, com o verbo no subjuntivo e sujeito anteposto ao verbo.

Diante do exposto, o autor separa a última sessão para explicar a colocação de pronomes átonos no Brasil, sendo que nem sempre a Gramática aceita como dignas certas tendências brasileiras, pois está presa, de acordo com Bechara (2015), a um critério de autoridade que a Sociolinguística pede que seja revisto, uma vez que, por diversas razões, na linguagem coloquial do Brasil, o pronome átono pode assumir posição inicial de período. Para fundamentar sua afirmação, cita o professor Martinez de Aguiar, para quem a colocação de pronomes obedece a um complexo de fatores, fonético (rítmico), lógico, psicológico (estilístico), estético, histórico. Portanto, difere das demais ramificações da língua portuguesa em outros países lusófonos e deve ser aceita não como erro, mas uma possibilidade.

Tabela 1: Levantamento das pesquisas em gramáticas tradicionais

\begin{tabular}{c|l|l}
\hline \multicolumn{1}{c|}{ Autores } & \multicolumn{1}{|c}{ Páginas } & \multicolumn{1}{c}{ Observações } \\
\hline Ferreira (2007) & $\begin{array}{l}15 \text { (7 de teoria e } \\
8 \text { de exercícios) }\end{array}$ & $\begin{array}{l}\text { Não diferencia norma-padrão } \\
\text { e norma culta }\end{array}$ \\
\hline Bechara (2015) & 5 (teoria) & Sem exercícios de aplicação \\
\hline
\end{tabular}

Fonte: As próprias autoras

\section{Análise dos dados}

Com vistas na distinção entre a norma-padrão e a norma culta, exemplificada pelos pronomes pessoais, percebemos que há ainda o ensino da gramática em si mesmo - o gramatiquês 4 -, como uma atitude normativista, não apresentando a norma apenas como uma das variedades da língua, com usos sociais determinados, tornando-a elemento invariável e inflexível.

De acordo com Faraco (2002),

Chamamos de gramatiquice ao estudo da gramática como um fim em si mesmo; e entendemos por normativismo a atitude diante da norma padrão que não consegue apreendê-la como apenas uma das variedades

${ }_{4}^{4}$ Termo pejorativo utilizado por Faraco (2002). 
da língua, com usos sociais determinados. Em conseqüência, toma-a como um monumento pétreo (invariável e inflexível) e condena como erro todas as formas que não estão de acordo com aquilo que está prescrito nos velhos manuais de gramática. Quando se tratou de organizar a partir do século XV e XVI, o ensino de língua vernácula foi o modelo pedagógico medieval que se tornou a referência. Quer dizer: transferiu-se para o ensino de língua materna uma metodologia que servia para o ensino de uma língua artificial (FARACO, 2002, p. 148).

Assim, é necessário um desprendimento dessa visão tradicionalista, a fim de um ensino da língua portuguesa contextualizada, utilizando-se de textos orais e escritos, com um uso efetivo pelo aluno, possibilitando o conhecimento das diversas práticas sociais de linguagem, assim como uma reflexão sobre a estrutura e o funcionamento social, relevantes para a sua inserção na sociedade, por meio do domínio fluente da fala e da escrita.

Podemos observar que no português brasileiro não há um padrão de pronúncia, e essa falta de normatização não prejudica a comunicação entre os falantes de comunidades de prática diferentes. Diante disso, questiona-se por que as pronúncias não afetam diretamente os falantes do português brasileiro, mas na escola há a necessidade da normatização de uma língua distante da realidade dos alunos. Tomando essa ideia, um recurso para o professor aproximar o ensino de português à linguagem dos estudantes é a utilização de músicas populares brasileiras contemporâneas e alguns poemas com linguagem culta que podem dialogar com as aulas de Literatura Brasileira.

São exemplos a música “Trevo”, de Anavitória (Anexo 1), do ano de 2016, e o poema "Balada do amor através das idades", de Carlos Drummond de Andrade (Anexo 2), do livro de 1930, em que observamos o uso intercalado das $2^{a}$ e $3^{\text {a }}$ pessoas do discurso (tu e você), o que seria incorreto perante a norma padrão, mas utilizado em vias cultas da língua. Na música, os trechos são: “Tu é trevo de quatro folhas, é manhã de domingo à toa" "Tu que tem esse abraço casa, se decidir bater asa”, “Quando aqui tu tá”. Essas construções podem ser justificadas pela estilística e musicalidade, mas não estão de acordo com a gramática, conforme a qual os versos deveriam ficar: "Tu és trevo de quatro folhas, és manhã de domingo à toa", "Tu que tens esse abraço casa, se decidires bater asa" "Quando aqui tu estás".

Percebemos o mesmo uso no poema de Drummond, com o trecho: "Eu te gosto, você me gosta", que deveria ficar: "Eu gosto de ti, tu gostas de mim" ou "Eu gosto de você, você gosta de mim", pois a regência do verbo "gostar” exige a preposição "de", afastando-se da língua espanhola, que poderia ser "Tu me gustas".

$\mathrm{O}$ mesmo fenômeno acontece no poema "O menino que carregava água na peneira" (Anexo 3), de Manoel de Barros, no trecho: "Você vai encher os vazios com as suas peraltagens, e algumas pessoas vão te amar por seus despropósitos", que também mistura as pessoas do discurso.

Quanto ao fenômeno da colocação pronominal, houve a inversão da próclise e da ênclise na música "Samba da volta" (Anexo 4) e nos poemas "Poema enjoadinho" 
(Anexo 5), de Vinícius de Moraes, e "A educação pela pedra” (Anexo 6), de João Cabral de Melo Neto. Na música, a construção original é: "E se atirou, me envolveu, me brincou", enquanto a norma prediz que a próclise não deve iniciar sintagmas verbais: "E atirou-se, envolveu-me, brincou comigo", pois a regência do verbo brincar exige a preposição "com". O mesmo observamos no "Poema enjoadinho", de Vinícius de Moraes, nas construções "Melhor não tê-los" e "Se iodifica", que ficam de acordo com a gramática normativa: "Melhor não os ter" e "Iodifica-se", pois a próclise é obrigatória com o atrativo e a ênclise, pelo sintagma verbal, assim como no poema de João Cabral de Melo Neto, no trecho: "Para quem soletrá-la", que deveria ser "Para quem a soletrar".

Desta forma, questionamos se há realmente a necessidade da norma-padrão na escrita, pois os dados evidenciam que a grafia padrão é eficiente e já é definida pelo vocabulário ortográfico, mas, como observado nos exemplos anteriores, a norma padrão não é realmente utilizada por nomes importantes da Literatura Brasileira e das Artes. Assim, se essas construções coloquiais são bem aceitas pelos intelectuais e pelo público, por que não, como Faraco (2008) afirma, considerar a linguagem normal como a linguagem normativa para a fala e a escrita?

\section{Considerações finais}

Ao longo desta discussão, observamos que o uso coloquial pode ser trabalhado de forma contextualizada com a Literatura, abordando os aspectos coloquiais da língua que são utilizados pela maioria dos falantes. O professor pode optar por uma aula contrastiva e trabalhar as variedades coloquial, culta e padrão, como formas existentes e usuais do português brasileiro, além de mencionar as contribuições contrárias do uso normativo, que também é uma variedade do português. Desta forma, demonstra-se ao aluno que uma mesma construção pode ser feita de diferentes maneiras e que não há uma sobreposição entre elas, mas a consciência de contextos aplicáveis ou não.

Faraco (2008) defende que existe uma forte tendência em se reificar e fetichizar a norma-padrão, isolando-a de seu contexto social, cultural e histórico, o que traz consequências negativas e perturbadoras para a efetiva padronização linguística no país, pois se torna artificial e anacrônico. Logo, é necessário contrapor-se a esse quadro, desafiando a criação de condições para uma crítica da atitude normativista, porque o importante é o efetivo domínio das práticas socioculturais de leitura e de produção de textos. Quanto à língua escrita, Bortoni-Ricardo (2004) explica que a uniformidade da ortografia garante sua funcionalidade, enquanto na modalidade oral se ensinam os recursos da variação para tornar a fala mais competente e conservar suas características sociodemográficas.

Por meio desta reflexão, podemos sugerir que uma possível alternativa para o ensino de língua portuguesa seja a organização dos professores dos anos iniciais da educação básica, não deixando toda a tarefa apenas aos pedagogos, e sim dividindo-as 
com profissionais de Letras e outras áreas relacionadas à educação, incumbindo ao pedagogo a tarefa de alfabetização, que já é muito importante. Quanto aos demais professores, com formações específicas em diversas áreas do conhecimento, caberia a discussão mais aprofundada acerca dessas temáticas, em especial os fenômenos de linguagem, pensando estritamente o ensino de língua portuguesa.

\section{ANÁLISIS CONTRASTANTE DE TEXTOS EN EL AULA}

Resumen: Nuestro objetivo en este artículo es analizar fenómenos encontrados en textos de los géneros poema y música que representan el lenguaje popular, acercándose del habla de los estudiantes y, a partir de esos datos, identificar lo que, según la norma estándar, presentaría desvíos gramaticales. A partir de las observaciones de los textos, buscamos identificar como la enseñanza de portugués en la escuela debe cubrir las diferentes posibilidades de uso de la lengua, que contemplan la modalidad culta, norma estándar y la variación lingüística. Para eso, utilizamos los estudios de Carlos Alberto Faraco (2002; 2008) y Stella Maris Bortoni-Ricardo (2004) como fundamentación del concepto de norma y da metodología de los Continuos de Letramiento, Monitoreo y Estilística. Para oponerse a las teorías de Pedagogía de Variación (FARACO, 2008; BORTONI-RICARDO, 2004), presentamos los conceptos gramaticales de los fenómenos analizados, basado en las gramáticas de Mauro Ferreira (2007) y Evanildo Bechara (2015). Avalados en las teorías, fuimos para el análisis del material que consiste en dos canciones populares y cuatro poemas modernistas brasileños. En este contexto, observamos como los autores emplean la colocación pronominal, la selección léxica y las personas del discurso, al principio fuera de la norma estándar, pero coherente para los estudiantes. De esa manera, creamos el contraste entre norma estándar y norma culta, presentando para los alumnos las varias formas de adecuación.

Palabras llave: Poema y música; Pedagogía de Variación; Sociolingüística; Normas.

\section{Referências:}

ANAVITÓRIA; IORC, Thiago. Trevo. Rio de Janeiro: Universal, 2016. Disponível em: https://www.youtube.com/watch?v=GiXHRwNTu_I. Acesso em 28 set. 2020.

ANDRADE, Carlos Drummond de. Balada do amor através das idades. In: ANDRADE, Carlos Drummond de. Alguma poesia. São Paulo:

Câmara Brasileira do Livro, 1930.

BARROS, Manoel de. O menino que carregava água na peneira. In: BARROS, Manoel de. Exercícios de ser criança. Rio de Janeiro: Salamandra, 1999.

BECHARA, Evanildo. Moderna gramática portuguesa. 38. ed. rev. ampl. Rio de Janeiro: Nova Fronteira, 2015.

BORTONI-RICARDO, Stella Maris. O estatuto do erro na língua oral e na língua escrita. In: GORSKI, Edair Maria; COELHO, Izete Lehmkuhl. Sociolinguística e ensino: Contribuições para a formação do professor de língua. Florianópolis: Editora da UFSC, 2004. 
FARACO, Carlos Alberto. Norma-padrão brasileira: desembaraçando alguns nós. In: BAGNO, Marcos (Org.). Linguística da norma. São Paulo: Edições Loyola, 2002.

FARACO, Carlos Alberto. Norma culta brasileira: desatando alguns nós. São Paulo: Parábola Editorial, 2008.

FERREIRA, Mauro. Aprender e praticar gramática. Ed. renovada. São Paulo: FTD, 2007.

MELO NETO, João Cabral de. A educação pela pedra. In: MELO NETO, João Cabral de. A educação pela pedra e depois. Rio de Janeiro: Nova Fronteira, 1997. MORAES, Vinicius de. “Poema enjoadinho”. In: MORAES, Vinícius. Antologia poética. Rio de Janeiro: Editora do Autor, 1960.

MORAES, Vinícius de. Samba da volta. In: MORAES, Vinícius. Rio de Janeiro: Tonga editora musical. 1974. Disponível em: https://www.youtube.com/ watch?v=MhNfOXmYIOs. Acesso em 28 set. 2020.

Recebido em 06 de abril de 2021

Aprovado em 07 de maio de 2021

\section{ANEXOS}

\section{Anexo 1 - Trevo (Anavitória)}

Tu é trevo de quatro folhas

É manhã de domingo à toa

Conversa rara e boa

Pedaço de sonho que faz meu querer acordar

Pra vida

Ai ai ai

$\mathrm{Tu}$, que tem esse abraço casa

Se decidir bater asa

Me leva contigo pra passear

Eu juro afeto e paz não vão te faltar

Ai ai ai

Ah, eu só quero o leve da vida pra te levar

E o tempo para, ah

É a sorte de levar a hora pra passear

Pra cá e pra lá, pra lá e pra cá

Quando aqui tu estás. 
Anexo 2 - Balada do amor através das idades

(Carlos Drummond de Andrade)

Eu te gosto, você me gosta

desde tempos imemoriais.

Eu era grego, você troiana, troiana mas não Helena.

Saí do cavalo de pau

para matar seu irmão.

Matei, brigamos, morremos. [...]

Anexo 3 - 0 menino que carregava água na peneira (Manoel de Barros)

[...] Você vai encher os vazios

com as suas peraltagens,

e algumas pessoas vão te amar por seus despropósitos!

\section{Anexo 4 - Samba da volta (Vinícius de Moraes)}

Você voltou, meu amor,

alegria que me deu

Quando a porta abriu

você me olhou, você sorriu, ah, você se derreteu

e se atirou, me envolveu, me brincou,

conferiu o que era seu [...]

\section{Anexo 5 - Poema enjoadinho (Vinícius de Moraes)}

Filhos... Filhos?

Melhor não tê-los!

Mas se não os temos

Como sabê-los? [...]

Engole água

Fica salgada

Se iodifica [...]

\section{Anexo 6 - A educação pela pedra (João Cabral de Melo Neto)}

Uma educação pela pedra: por lições;

para aprender da pedra, frequentá-la;

captar sua voz inenfática, impessoal

(pela de dicção ela começa as aulas). 
A lição de moral, sua resistência fria ao que flui e a fluir, a ser maleada;

a de poética, sua carnadura concreta;

a de economia, seu adensar-se compacta:

lições da pedra (de fora para dentro,

cartilha muda), para quem soletrá-la. 